\title{
Surface Modification of Film Chitosan Materials With Aldehydes for Wettability and Biodegradation Control
}

\section{Ekaterina Bryuzgina ( $\sim$ cher-ekaterina18@yandex.ru )}

Volgograd State Technical University: Volgogradskij gosudarstvennyj tehniceskij universitet https://orcid.org/0000-0002-9627-334X

\section{Vitaliya Yartseva}

Volgograd State Technical University: Volgogradskij gosudarstvennyj tehniceskij universitet

\section{Evgeny Bryuzgin}

Volgograd State Technical University: Volgogradskij gosudarstvennyj tehniceskij universitet Oleg Tuzhikov

Volgograd State Technical University: Volgogradskij gosudarstvennyj tehniceskij universitet

\section{Alexander Navrotskiy}

Volgograd State Technical University: Volgogradskij gosudarstvennyj tehniceskij universitet

\section{Research Article}

Keywords: chitosan, film materials, matrices for tissue engineering, Schiff bases, biodegradation, cytotoxicity

Posted Date: June 7th, 2021

DOl: https://doi.org/10.21203/rs.3.rs-547929/v1

License: (a) This work is licensed under a Creative Commons Attribution 4.0 International License. Read Full License

Version of Record: A version of this preprint was published at Polymer Bulletin on January 30th, 2022. See the published version at https://doi.org/10.1007/s00289-021-04039-4. 


\section{Surface modification of film chitosan materials with aldehydes for wettability and biodegradation control}

Ekaterina Bryuzgina* (cher-ekaterina18@yandex.ru)

ORCID 0000-0002-9627-334X

Vitaliya Yartseva (yvita1995@gmail.com)

ORCID 0000-0002-8678-6539

Evgeny Bryuzgin (bryuzgin_e@ mail.ru)

ORCID 0000-0002-2930-1910

Oleg Tuzhikov (oi_tuzhikov@vstu.ru)

ORCID 0000-0002-5365-6375

Alexander Navrotskiy (navrotskiy@ vstu.ru)

ORCID 0000-0001-9500-3607

Chemical Engineering Faculty, Volgograd State Technical University, Volgograd, 400005, Russia

* Corresponding author at: Chemical Engineering Faculty, Volgograd State Technical University, Volgograd, 400005, Russia

E-mail address: cher-ekaterina18@yandex.ru

\section{Abstract}

Chitosan is one of prospective polymer for use in regenerative medicine which has unique properties such as biocompatibility, biodegradability, antimicrobial, antiinflammatory, and antitumor potency. In this article, we study the peculiarities of the surface modification of chitosan films with carbonyl-containing compounds, which differed both in molecular characteristics and in their hydrophilic and hydrophobic properties. The potential for controlling the biodegradation of the resulting materials has been established, which can be used in the creation of wound dressings. Both the destruction time and lyophilic properties of the surface depend on the length of the modifier's hydrocarbon radical. The contact angle and water absorption of obtained film materials correlate with hydrophobicity, which estimated by the calculated value of the hydrophilic-lipophilic balance (HLB). The 
cytotoxicity of modified chitosan films was studied, and it was found that they are non-toxic (cytotoxic index of $<50 \%$ ) for human skin cell cultures, which shows their potential for use in the creation of materials for skin protection and external wound healing.

Keywords: chitosan; film materials; matrices for tissue engineering; Schiff bases; biodegradation; cytotoxicity.

\section{Declarations}

\section{Funding}

This study was carried out with financial support from the Russian Science Foundation as part of project No. 19-73-10147.

\section{Acknowledgements}

The authors would like to thank Falcon Scientific Editing (https://falconediting.com) for proofreading the English language in this paper.

\section{Conflicts of interest/Competing interests}

The authors declare that they have no conflict of interest.

\section{Availability of data and material}

Not applicable

\section{Code availability}

Not applicable

\section{Authors' contributions}

Conceptualization: Ekaterina Bryuzgina, Evgeny Bryuzgin

Investigation: Ekaterina Bryuzgina, Vitaliya Yartseva

Writing - Original Draft: Ekaterina Bryuzgina

Resources Evgeny Bryuzgin

Writing - Review \& Editing Evgeny Bryuzgin, Oleg Tuzhikov, Alexander Navrotskiy

Funding acquisition: Evgeny Bryuzgin

Supervision: Oleg Tuzhikov

Project administration: Alexander Navrotskiy

\section{Ethics approval}


Not applicable

Consent to participate

Not applicable

Consent for publication

Not applicable 


\section{INTRODUCTION}

Since the early 2000s, there has been an increasing interest in biodegradable polymers and materials based on them in regenerative medicine [1]. Unlike biologically inert implants, these biomaterials are designed for controlled degradation and promote the growth of new tissues or support the growth of the body's own cells [2-7]. In addition to biodegradability, materials for tissue engineering should have biocompatibility, i.e., they should be incorporated into the body without causing adverse clinical implications [4, 8], and biological potency, such as antimicrobial, anti-inflammatory, and antitumor potency $[9,10]$.

One of these polymers is chitosan, with chitosan-based materials being able to degrade not only in the environment $[11,12]$ but also enzymatically in the human body [13]. It is biocompatible, biologically potent [14] and biodegradable [15], which make this polymer promising for use in regenerative medicine [16] for healing burns and wounds without scarring $[17,18]$.

Owing to the presence of functional hydroxyl, carboxyl, carbonyl, hemiacetal, and amine groups, polysaccharides are hydrophilic polymers that swell to a limited extent in water. Thus, materials of this kind lose their shape in a humid environment, including in the human body [1, 19]. It is known that the hydrophilicity of chitosan accelerates its biodegradability in the presence of moisture due to the active reproduction of microorganisms in such an environment and the appearance of enzymes and ions in water that affect the degradation kinetics [20]. Moreover, imparting hydrophobicity with contact angles on the order of $120^{\circ}$ and higher makes it impossible for such materials to absorb wound exudates and therefore lead to rejection by the body. Thus, it is necessary to regulate the hydrophilic-hydrophobic properties of such materials to control the destruction time.

Aldehydes are effective modifying agents for chitosan [21-26] that retain a wide range of its biological potency. Interaction with aldehydes leads to the formation of Schiff bases and to a change in the wettability of chitosan-based materials [27]. There are two approaches for the chemical modification of chitosan 
with low molecular weight [28] and polymeric [29] modifiers. The first one involves chitosan dissolution in acetic or lactic acid in the presence of ethanol at moderate temperatures for a long time [30]. The disadvantage of this method is the formation of partially cross-linked products due to intermacromolecular interactions, which impede film formation. The simplest and most promising method is the surface treatment of chitosan-based materials (films, fibers, sponges, etc.) with alcohol and aqueous solutions of aldehydes at room temperature [31-33].

Research in this area is mainly devoted to the study of the interaction of chitosan dissolved in acetic acid with individual carbonyl-containing modifying agents. The nature effect of the aldehyde on the polysaccharide properties is practically not covered, and the study of lyophilic properties of the resulting materials, which affect their destruction time, is beyond the scope of this article. The difficulty of comparative analysis of these publications lies in the fact that in their works the authors used chitosan samples that differed in nature, molecular weight, molecular weight distribution, degree of deacetylation, degree of crystallinity, etc. The aforementioned factors affect the deformation and strength characteristics of the resulting films and fibers and the reactivity of chitosan.

This study used chitosan from the same batch; in addition, an extended set of aldehydes [34] were used, which differed both in molecular characteristics and in their hydrophilic and hydrophobic properties (soluble and slightly soluble in water or in organic solvents). This enabled us to conduct a comparative assessment of the structural organization and the physical, mechanical, and lyophilic properties of the chitosan films upon surface modification with aldehydes of different chemical composition.

This study aimed to investigate the peculiarities of modification of chitosan films with aldehydes for the creation of materials that have controlled wettability, biodegradability, and biocompatibility with human tissues.

\section{MATERIALS AND METHODS}




\subsection{Materials and Reagents}

Chitosan from Ltd "Bioprogress", Russia (M = $200 \mathrm{kDa}$, degree of deacetylation $=82 \%$ ); glacial acetic acid (analytical grade, "Vekton", Russia); methanol (chemically pure, "Vekton", Russia); distilled water; sodium hydroxide (analytical grade, "Vekton", Russia); formic aldehyde (formaldehyde (FA), 37.5\% aqueous solution - formalin, "Vekton", Russia); acetaldehyde (AA, 40\% aqueous solution, "Vekton", Russia); acrolein (Ac, technical product of Volzhsky Orgsintez JSC, Russia $(96.3 \%$ basic substance, $3.5 \%$ moisture, $0.2 \%$ hydroquinone stabilizer)); propionic aldehyde (PA, chemically pure, Acros Organics); isovaleraldehyde (IVA, chemically pure, Acros Organics); salicylic aldehyde (SA, chemically pure, "Vekton", Russia).

\subsection{Preparation of a chitosan films}

The preparation of solutions and the formation of chitosan-based materials with subsequent reduction from the salt to the basic form were carried out according to methods described earlier $[34,35]$. The dried films had a thickness of $30-40 \mu \mathrm{m}$ and were used for further studies of structural, physical, mechanical, hydrophilic, and hydrophobic properties and for determining their biocompatibility with human skin cells.

\subsection{Modification of chitosan films with aldehydes}

The film sample was placed separately in a bath with $40 \mathrm{~mL}$ of aldehyde solutions of various concentrations in water or alcohol. The film was cured for 25$30 \mathrm{~min}$ in $0.005-0.05 \%$ aqueous solutions of acrolein and $0.5-5 \%$ alcohol solutions of the remaining aldehydes, which corresponded to the optimal modification time. To remove unreacted aldehyde from the film surface, the samples were washed with water or alcohol and then subjected to Soxhlet extraction with methyl alcohol for $10 \mathrm{~h}$. The washed samples were dried at room temperature until a constant weight.

The degree of grafting was determined gravimetrically as the ratio of the mass of the grafted aldehyde to the mass of the initial modified chitosan-based material, 
and the grafting efficiency was determined as the ratio of the mass of the grafted modifier to the mass of aldehyde in the modification solution.

The resulting Schiff bases were reduced by film surface treatment with excess $(20 \mathrm{~mL}$ of a $2 \%$ solution) sodium borohydride in water for $24 \mathrm{~h}$ at room temperature [36]. The reduced samples were washed in containers with water until neutral reaction of the medium and dried at $40^{\circ} \mathrm{C}$ until reaching a constant weight.

\subsection{Methods}

Structural studies were carried out by IR spectroscopy using a SPECORD M82 (Germany) and with an attenuated total reflection (ATR) accessory using an InfraLUM FT-08 (Russia) apparatus. Before spectral measurements, the samples were cured at room temperature in a desiccator with a relative humidity of $66 \%$ (over sodium nitrate). The IR absorption spectra were interpreted using literature data according to assignments of frequencies of functional groups in the spectra of analogous compounds.

The strength characteristics of the resulting films were determined at a tensile speed of $10 \mathrm{~mm} / \mathrm{min}$ using a Zwicki Line " $5 \mathrm{kN}$ zwicki" (Germany) tensile testing machine according to GOST 14236-81. Samples with a size of $2 \times 20 \mathrm{~mm}$ were used for testing. Before testing, the samples were conditioned for at least $16 \mathrm{~h}$ at a temperature of $23 \pm 2{ }^{\circ} \mathrm{C}$ and a relative humidity of $66 \%$ (over sodium nitrate) according to GOST 12423-66.

The hydrophilic and hydrophobic properties of the initial and modified chitosan films were studied by determining the amount of moisture sorbed by the film samples from the change in the sample mass in desiccators with a moisture content of $0 \%$ (over phosphorus pentoxide) and $98 \%$ (over a saturated solution of potassium sulfate). In addition, the contact angle of the surface was determined using a DataPhysics OCA 15EC apparatus (Germany) [37]. The measurements were carried out by applying drops of distilled water with a volume of 5-7 $\mu \mathrm{L}$ on the surface of the test material at room temperature with the contact angle of a sessile drop calculated according to the Young-Laplace method. 
The HLB (hydrophilic-lipophilic balance) value was calculated using the Davis method (formula (1)) [38]:

$$
H L B=7+\sum_{i=1}^{m} H L B_{i}-0,475 \cdot n,
$$

where $m$ is the number of hydrophilic groups in the molecule;

$H L B_{i}$ is the number for the $\mathrm{i}$-th hydrophilic group; and

$n$ is the number of lipophilic groups in the molecule.

Biodegradability was studied using chitosan films in the form of $20 \times(3-4)$ mm samples that were used as a substrate. The test samples were subjected to in vitro soil degradation. The soil was "activated" at a temperature of $20 \pm 5^{\circ} \mathrm{C}$ for 30 days. During this period, the soil was stirred on a daily basis, and the moisture content (should be $30 \pm 5 \%$ ) was determined once a week. For this purpose, the soil was moistened with distilled water every $48 \mathrm{~h}$. The $\mathrm{pH}$ of the aqueous extract in the soil was determined before testing. The soil was considered fit for testing at pH 6-7.5. Afterwards, four $20 \times(3-4)-\mathrm{mm}$ strips of unmodified and four samples of each modified chitosan were oven dried at $105 \pm 2{ }^{\circ} \mathrm{C}$ and weighed, followed by determination of the thickness and width of the samples. The samples were then placed in a tray with activated soil in wells and digged in. The location of the films was marked with markers. The films were removed, washed in water, oven dried at $105 \pm 2^{\circ} \mathrm{C}$, weighed, and subjected to determination of thickness and width of the samples every 15 days (up to 75 days) [39].

The cytotoxicity of the chitosan-based matrices was determined according to a method described earlier [34, 40]. A toxicity measure for the materials is the cytotoxic index $(C I)$, which was calculated using Formula (2). Cultured plastic was used as a comparison object:

$$
C I=\frac{(a-b) \cdot 100 \%}{a},
$$

where $a$ is the reference optical density (supernatant was cultured plastic without the addition of the preparation), and

$b$ is the test optical density (supernatant with the addition of the preparation). 
A preparation was considered non-toxic to cells if the cytotoxic index is in the range of 0 to $50 \%$ of the reference.

\section{DISCUSSION}

Aqueous solutions of acetic or formic acids, which form the corresponding salts with chitosan, were used as a solvent to obtain chitosan films, sponges, and fibers. Dry chitosan films are homogeneous, transparent, colorless, and non-brittle materials in which the ultimate tensile stress and elongation are 60-70 MPa and 7$10 \%$, respectively $[41,42]$.

This study involved the surface modification of the chitosan films with aldehydes to control the hydrophilic and hydrophobic and physical and chemical characteristics. The formed Schiff bases retained the antifungal, antibacterial, antimicrobial, anti-inflammatory, and antitumor biological potencies of the polysaccharide [4]. The reaction of the amino group of chitosan with the aldehyde group of the modifier on the film surface proceeds according to the scheme shown in Figure 1.

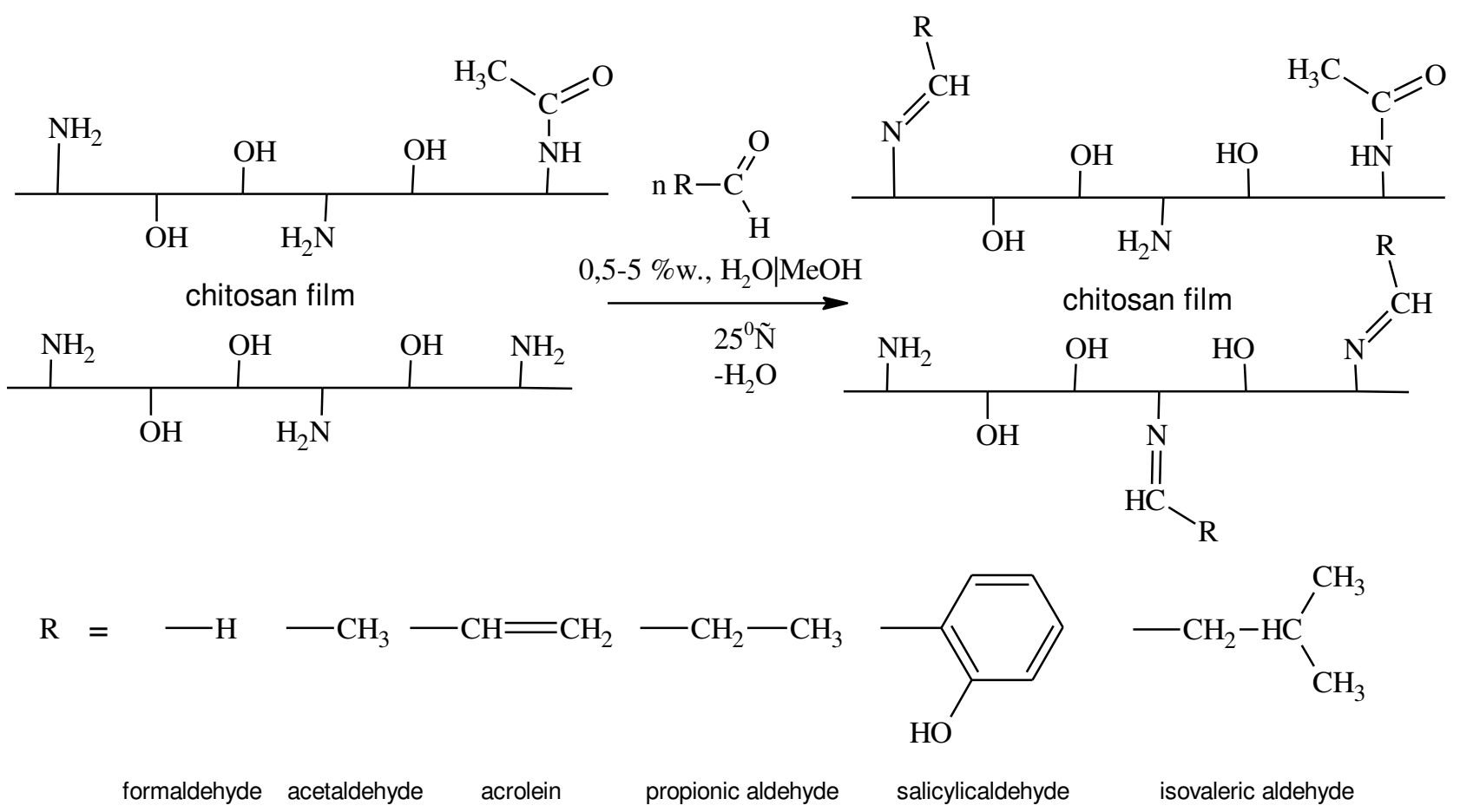

Fig.1 Interaction of chitosan with aldehydes with the formation of Schiff bases

Primary amines easily react with aldehydes, thus changing the structural and thermal characteristics of the modified film materials. The modifiers can be 
selected for study according to the increase in hydrophobicity subject to the HLB (hydrophilic-lipophilic balance) values of the hydrocarbon substituents added to chitosan during the reaction (Table 1).

Table 1 HLB (hydrophilic-lipophilic balance) values of the hydrocarbon substituents of the modifiers added to chitosan during the reaction

\begin{tabular}{lc}
\hline $\mathrm{R}$ (hydrocarbon substituent) & $\mathrm{HLB}, \mathrm{cu}$ \\
\hline $\mathrm{H}-$ & 0 \\
$\mathrm{CH}_{3}-$ & -0.475 \\
$\mathrm{CH}_{2}=\mathrm{CH}-$ & -0.950 \\
$\mathrm{CH}_{3}-\mathrm{CH}_{2-}$ & -0.950 \\
$\mathrm{HO}_{-} \mathrm{C}_{6} \mathrm{H}_{4-}^{-}$ & -0.950 \\
$\left(\mathrm{CH}_{3}\right)_{2} \mathrm{CH}-\mathrm{CH}_{2-}$ & -1.900 \\
\hline
\end{tabular}

Because the use of hydrophobic agents on smooth surfaces enables contact angles of no more than 120 degrees [43], it is necessary to study the effect of the structure of aldehydes on the morphology and texture of the surface of chitosanbased films. It was found that surface modification with formic (FA) and acetic (AA) aldehydes slightly affects the hydrophobicity of the films, while reducing the strength characteristics, which would be expected in accordance with Table 1. Therefore, further studies involved acrolein (Ac), propionic (PA), salicylic (SA), and isovalerial (IVA) aldehydes.

The structures of the resulting compounds were confirmed by IR spectroscopy (Figure 2). The IR spectra of the modified chitosan films were characterized by $\mathrm{C}=\mathrm{N}$ bond vibrations at $1632 \mathrm{~cm}^{-1}$, which are characteristic of imines but not typical for chitosan. However, there were no vibrations for the free aldehyde groups at approximately $1665 \mathrm{~cm}^{-1}$. The IR spectra of chitosan films treated with acrolein (Ac) have planar vibration frequencies at $995-985 \mathrm{~cm}^{-1}$, corresponding to the vinyl group. 


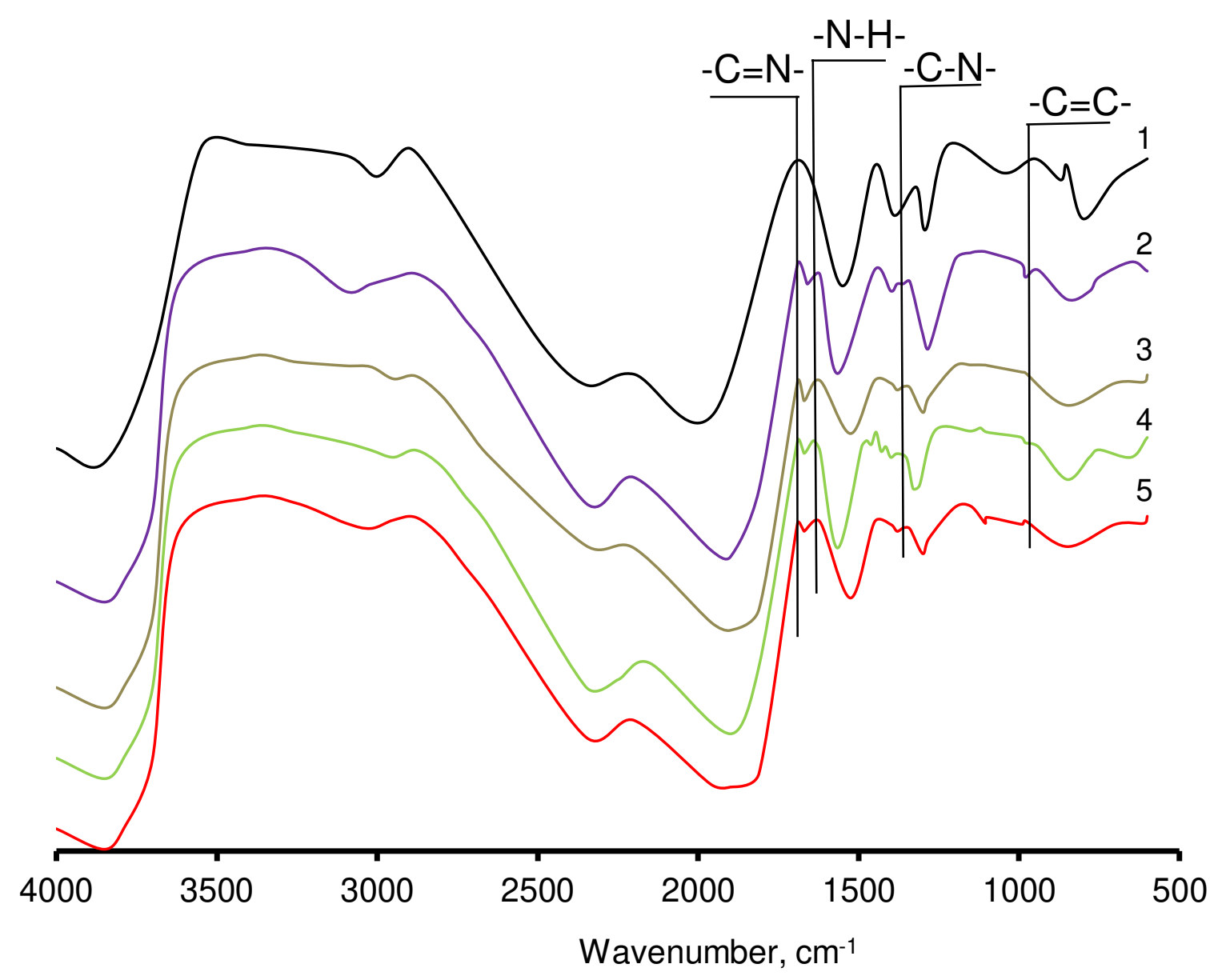

Fig.2 IR spectra of the initial chitosan film (1) and chitosan film treated with $0.0125 \%$ Ac solution (2), 2.5\% PA solution (3), $2.5 \%$ SA solution (4), and 2.5\% IVA solution (5)

In addition, the spectra of the chitosan films were obtained using the attenuated total reflection (ATR) method (Figure 3). In the wavelength range of 1500 to $1700 \mathrm{~cm}^{-1}$, there was also an increase in the absorption intensity at $1652 \mathrm{~cm}^{-1}$ (for modified films), the intensity of which changed upon interaction with aldehydes. However, there was a decrease in the peak intensity at $1581 \mathrm{~cm}^{-1}$ (amino group), which indicated a decrease in the number of amino groups, indicating the formation of imino groups. 


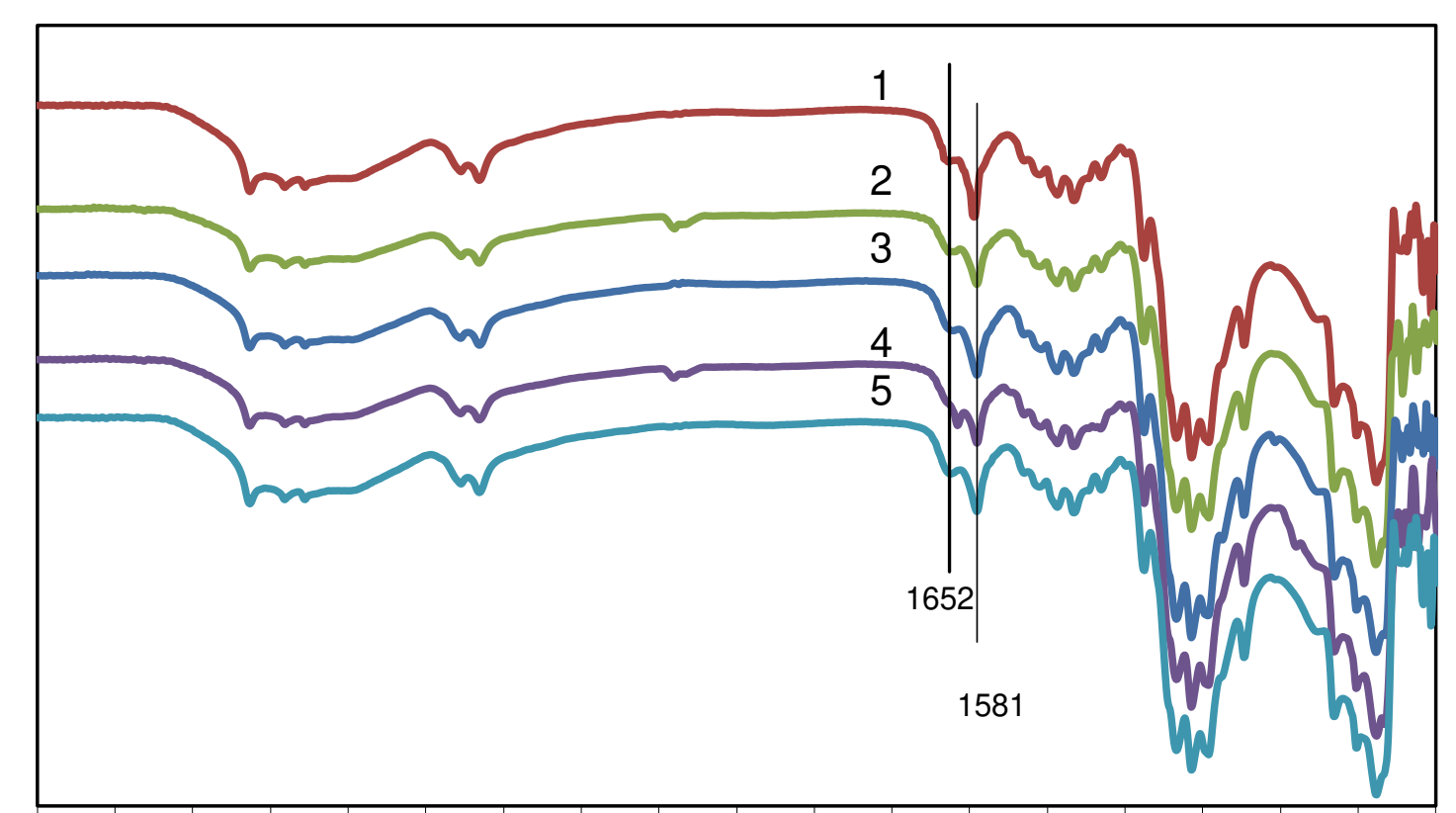

4000380036003400320030002800260024002200200018001600140012001000800600400 Wavenumber, $\mathrm{cm}^{-1}$

Fig.3 IR spectra (ATR accessory) of the chitosan films (1) treated with $0.0125 \%$ Ac solution (2), 2.5\% PA solution (3), $2.5 \%$ SA solution (4), and $2.5 \%$ IVA solution (5)

We previously showed that the optimal concentration of aldehyde in the modification solution was 0.0125 wt.\% for Ac [34]. Table 2 shows that the greatest degree of grafting was achieved by using propionaldehyde as a modifier, with the modification efficiency decreasing with an increase in the concentration of aldehydes, which was due to the filling of available amino groups on the material surface of the film.

Table 2 Grafting of aldehydes onto chitosan films

\begin{tabular}{cccc}
\hline \multirow{2}{*}{$\begin{array}{c}\text { Concentration of } \\
\text { modification } \\
\text { solution, \% }\end{array}$} & \multicolumn{3}{c}{ Degree of grafting, \% } \\
\cline { 2 - 4 } & PA & SA & IVA \\
\hline 0.05 & 0.25 & 0.25 & 0.22 \\
0.10 & 0.47 & 0.28 & 0.26 \\
0.50 & 0.51 & 0.39 & 0.30 \\
1.00 & 0.67 & 0.63 & 0.35 \\
2.50 & 0.82 & 0.75 & 0.53 \\
3.00 & 0.95 & 0.82 & 0.68 \\
4.00 & 1.04 & 0.92 & 0.80 \\
5.00 & 1.19 & 1.16 & 1.04 \\
\hline
\end{tabular}


The optimal concentration of the modifier can be estimated by the dependences of the strength characteristics (Figure 4a, b) and hydrophilic and hydrophobic characteristics (Figure 4c, d) on the degree of grafting at a film thickness of $60 \mu \mathrm{m}$ and IVA, SA, and PA modification times of 25-30 min.
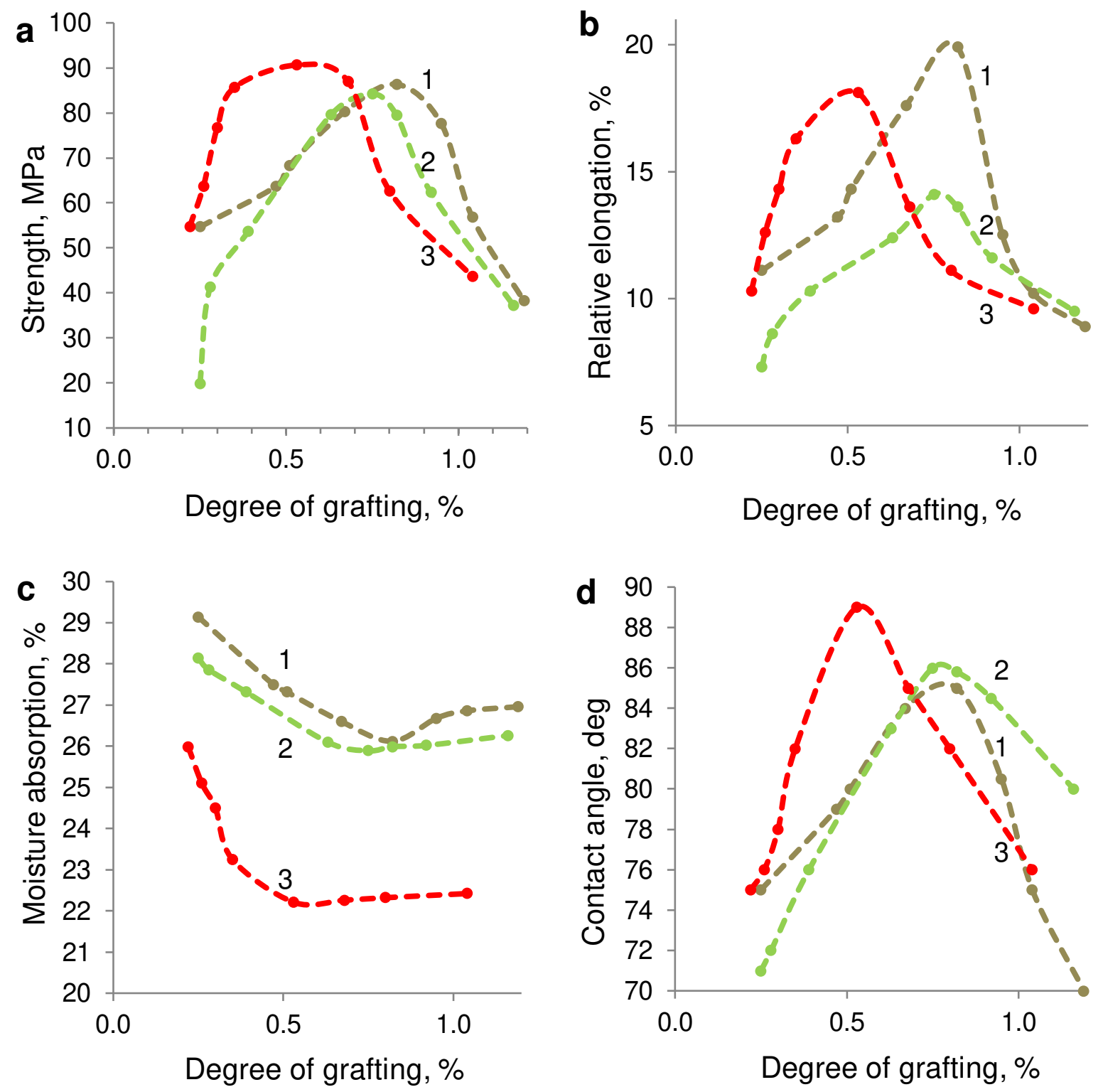

Fig.4 Dependence of the strength characteristics (a, b) and lyophilic characteristics (c, d) of the modified chitosan film on the degree of grafting of modifier:

$$
\text { PA (1), SA (2), and IVA (3) }
$$

The highest contact angle without compromising strength characteristics was achieved at a mass concentration of aliphatic saturated aldehydes in the modified solution of $2.5 \%$, i.e., at the degree of grafting of 0.82 for PA, 0.75 for SA, and 0.53 for IVA. The extreme nature of the dependences was likely due to the 
anisotropy of properties in different directions of the film materials, which was due to the reorientation of macromolecules during molding and drying as well as due to the fact that treatment modified only the surface and near-surface layers of the films without penetration of the modifier into the bulk of the samples.

The effects of surface modification of chitosan on the strength and lyophilic characteristics of the formed materials are described in Table 3.

Table 3 Strength and lyophilic properties of chitosan-based film materials

\begin{tabular}{ccccc}
\hline Sample & $\mathrm{R}^{1}$, & $\mathrm{A}^{2}$, & $\mathrm{W}^{3}$, & $\mathrm{CA}^{4}$, \\
& $\mathrm{MPa}$ & $\%$ & $\%$ & $\mathrm{deg}$ \\
\hline Chitosan & $65 \pm 4$ & $8 \pm 2$ & $40 \pm 3$ & $65 \pm 4$ \\
Modifier - 2.5\% PA solution in MeOH & $86 \pm 3$ & $19 \pm 2$ & $26 \pm 4$ & $85 \pm 2$ \\
Modifier - 2.5\% SA solution in MeOH & $84 \pm 3$ & $14 \pm 2$ & $24 \pm 3$ & $86 \pm 2$ \\
Modifier - 2.5\% IVA solution in MeOH & $90 \pm 4$ & $18 \pm 2$ & $22 \pm 2$ & $89 \pm 3$ \\
Modifier - 0.0125\% Ac solution in water & $110 \pm 3$ & $6 \pm 2$ & $13 \pm 3$ & $108 \pm 2$ \\
\hline
\end{tabular}

${ }^{1} \mathrm{R}$ is the tensile strength

${ }^{2} \mathrm{~A}$ is the ultimate elongation

${ }^{3} \mathrm{~W}$ is the moisture absorption

${ }^{4} \mathrm{CA}$ is the contact angle

The strengths of the modified chitosan films increase in the following order of modifiers: SA $<$ PA $<$ IVA $<$ Ac. Relative elongation increases in the following order of modifiers: Ac $<$ SA $<$ IVA $<$ PA.

Based on the structure of the alkyl radical in the aldehyde, it was expected that modification with isovaleraldehyde would impart the highest hydrophobicity to the chitosan films. However, it turned out that the Schiff bases based on chitosan and acrolein are superior to the used modifiers in these terms (the contact angle was $\approx 110$ degrees). This can be explained by the presence of $-\mathrm{N}=\mathrm{C}-\mathrm{C}=\mathrm{C}-$ conjugated bonds in the structure of the resulting compounds and by the greater diffusion of acrolein deep into the films (which was due to the treatment of the 
films with an aqueous solution of this modifier, while the rest were dissolved in alcohols).

Therefore, the hydrophilic and lipophilic balance data did not correlate with the values of moisture absorption and contact angle only in the case of acrolein (Figure 5), with the rest of the modifiers forming a FA $<$ AA $<$ PA $<$ SA $<$ IVA order in terms of the combination of hydrophilic and hydrophobic properties. Thus, the reactions in all free amino groups are expected to an increase in hydrophobicity depending on the length of the hydrocarbon radical.

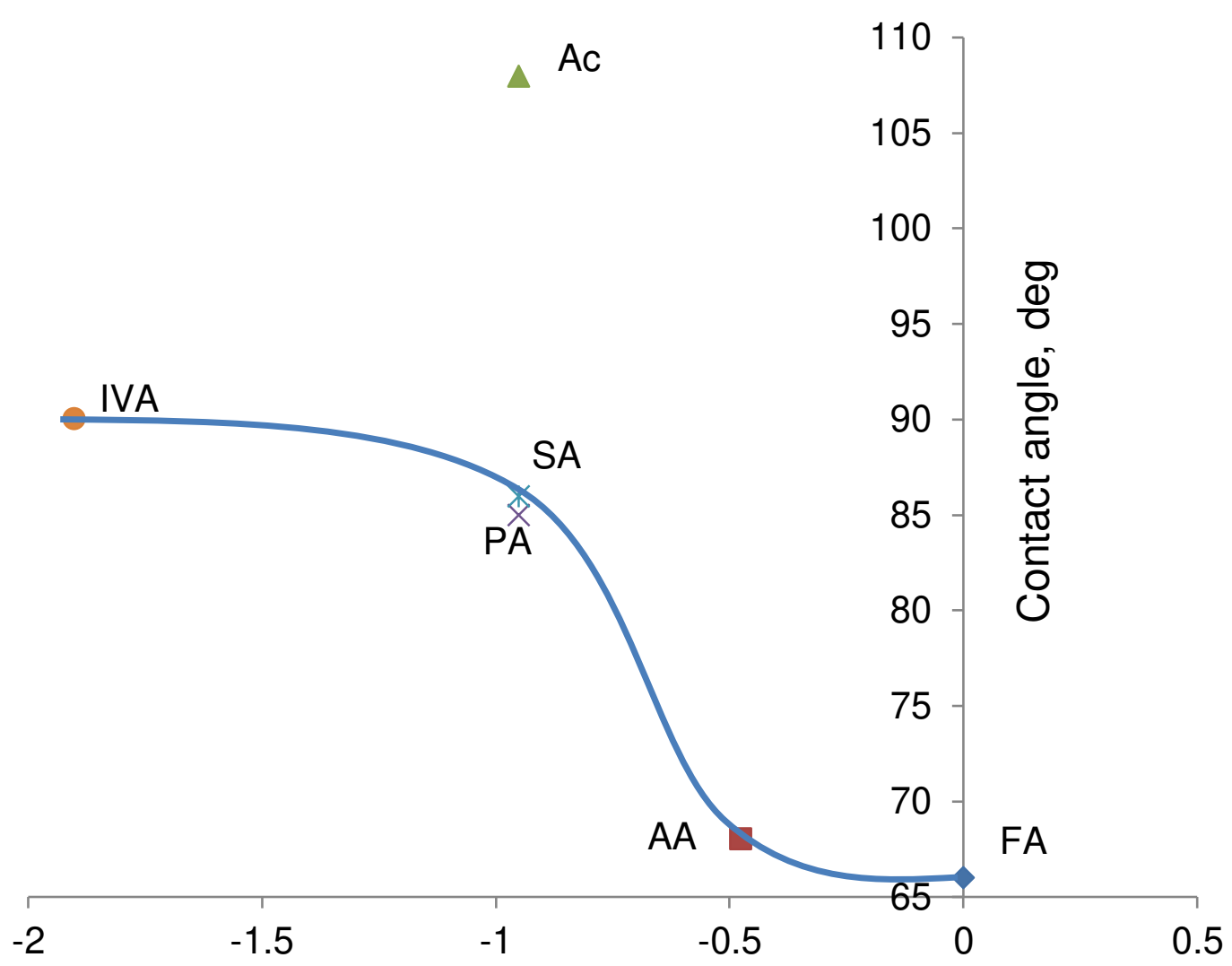

HLB, cu

Fig.5 Comparison of the contact angles of modified chitosan films with HLB data of hydrocarbon substituents of aldehydes

To estimate the decomposition time, the surface-modified chitosan film samples were subjected to in vitro soil degradation. Our study of the decomposition of the chitosan films showed (Figure 6) that the initial chitosan samples with a contact angle of $66^{\circ}$ showed $99 \%$ soil biodegradation within 75 days. The weight losses of the samples treated with aldehydes with contact angles 
of $85-108^{\circ}$ were $70 \%$ for salicylic aldehyde and $56 \%$ for acrolein. This is indicative of the potential for controlling the decomposition time of chitosan-based film materials by means of surface wettability regulation.

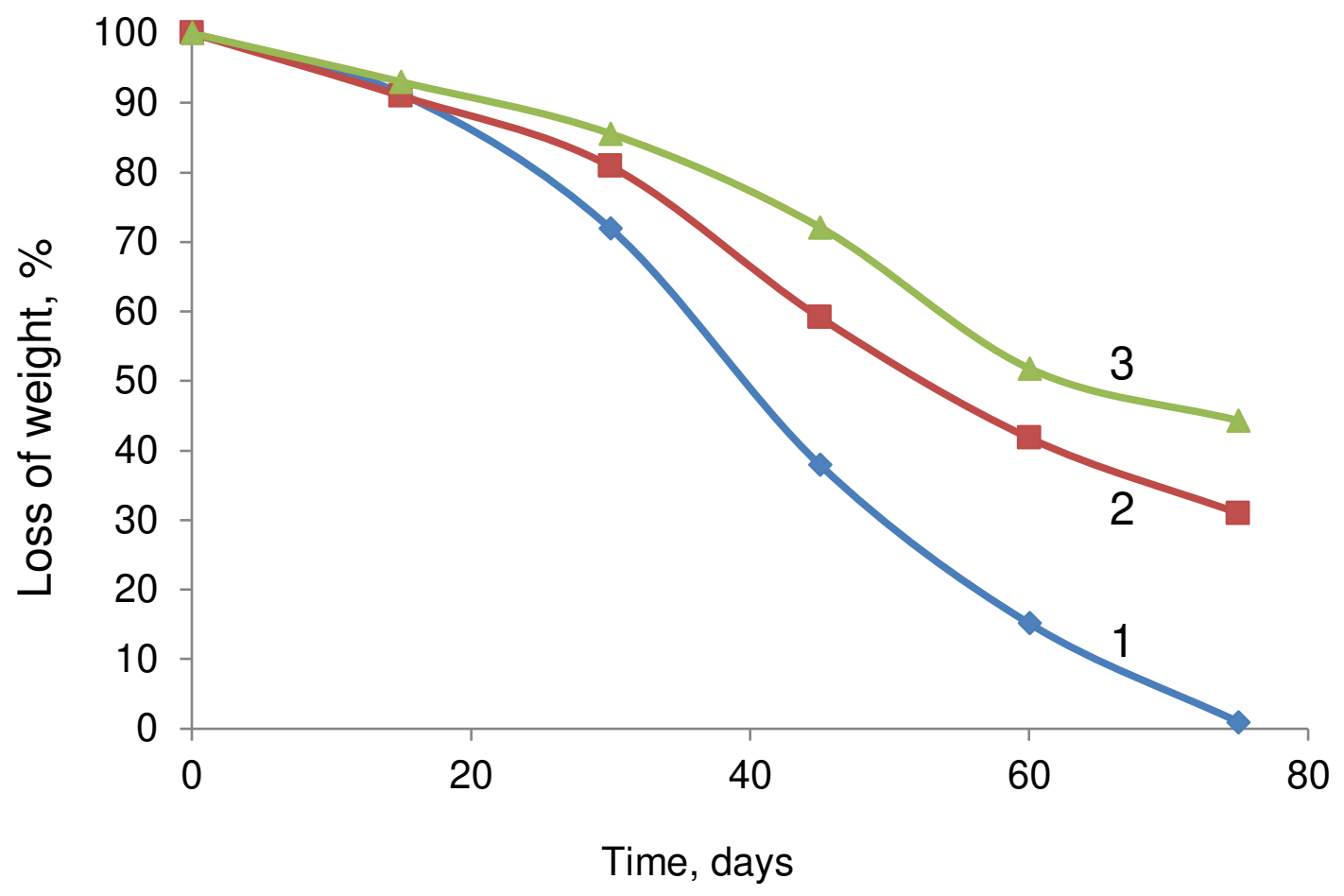

Fig.6 Biodegradability of the initial chitosan films (1) and chitosan films modified with salicylic aldehyde (2) and acrolein (3)

The MTT assay findings were used to select the materials for pharmacology, which were the least toxic for normal human cells, by monitoring the change in the number of cells on the substrate. The cytotoxicity of a particular preparation was determined according to the reduction reaction of the yellow tetrazolium salt (MTT) by mitochondrial dehydrogenases of living cells to water-insoluble purple formazan crystals. Formazan crystals (MTT-f) were dissolved in DMSO, and the optical density was determined using a colorimeter (data are shown in Figure 7). Previously [34], we presented results for the initial chitosan films and chitosan films modified with acrolein. 


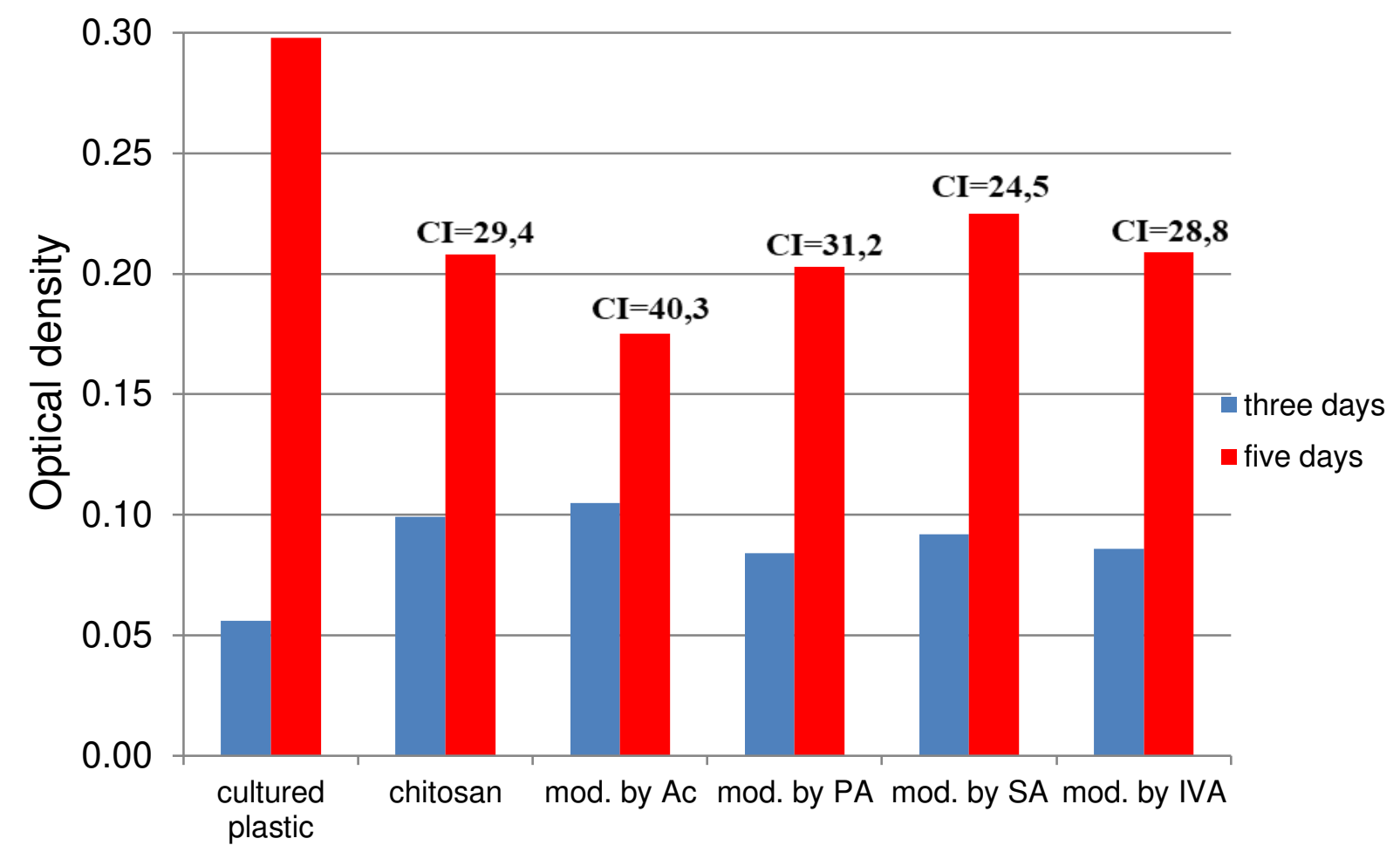

Fig.7 Changes in proliferation of human dermal fibroblasts on unmodified and modified chitosan films

The number of human dermal fibroblasts on the chitosan films significantly increased after 5 days of cultivation compared with that of films subjected to a 3day cell cultivation, which indicated the ability of the material to form new cells. There was a clear difference in the proliferative activity of cells during their cultivation on pure chitosan films and on films modified with aldehydes.

Of note, the films modified with PA, SA, IVA demonstrated faster cell proliferation than films that were modified with Ac.

The toxicity measure for materials is the cytotoxic index $(C I)$. The cytotoxic effect on human skin cells was estimated by counting viable cells in the chamber before and after their incubation with the preparation.

Calculation of the cytotoxic index requires determination of the optical density of the test object, which was cultured plastic. In this study, this was 0.298 after 5 days of cultivation. Afterwards, the indices shown in Figure 7 were determined using formula (2).

The studies conducted enabled us to determine the concentrations of compounds that caused $50 \%$ inhibition of cell survival. Thus, the tested materials 
showed the ability to grow new cells, and their toxicity was within the safe range (less than $50 \%$ of reference). However, the greatest effect was observed after 5 days of cell incubation. Among the films tested, those modified with SA and IVA demonstrated the best results, with their cytotoxic indices being below the index of the initial chitosan.

Schiff bases formed on the surface of chitosan materials containing imino groups are unstable in an alkaline medium at moderate temperatures; therefore, their further use requires additional reduction by treatment with sodium borohydride, which follows the scheme shown in Figure 8 [44].

$$
\mathrm{NaBH}_{4}+2 \mathrm{H}_{2} \mathrm{O} \longrightarrow \mathrm{NaBO}_{2}+4 \mathrm{H}_{2}
$$

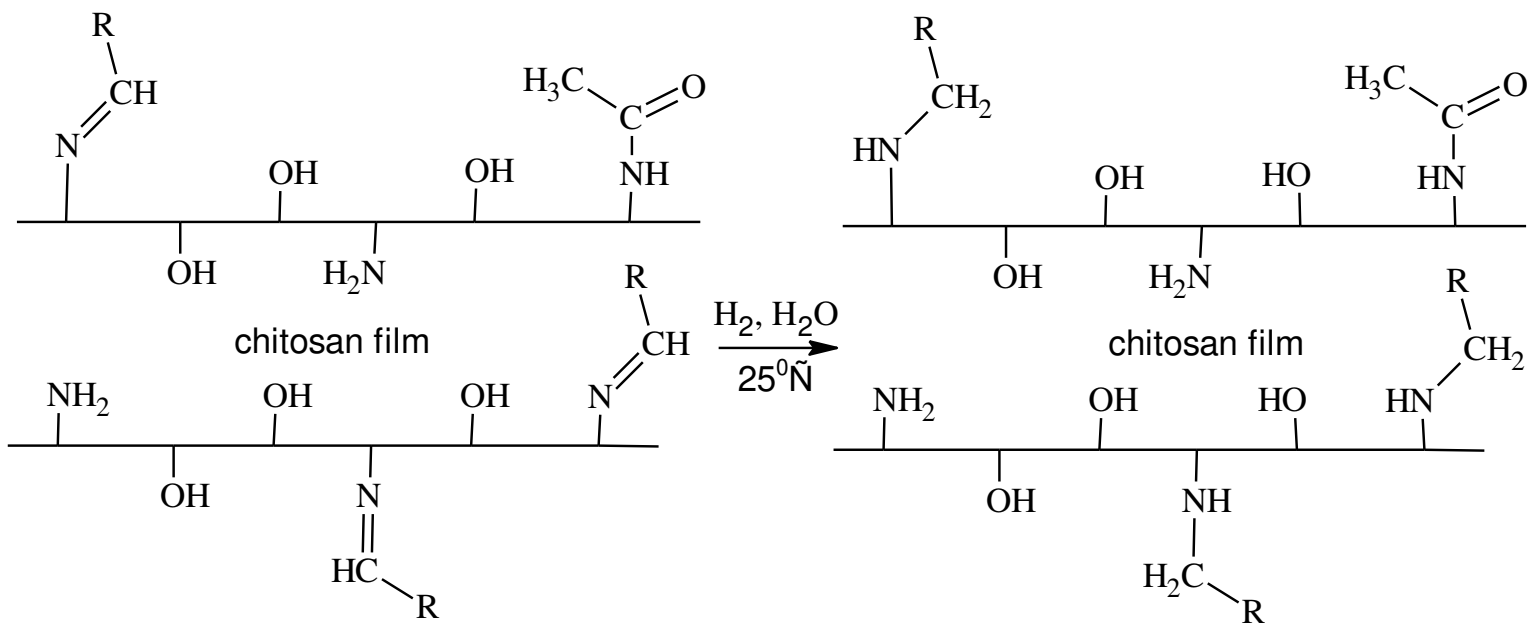

Fig.8 Reduction of resulting Schiff bases on chitosan films upon modification with aldehydes

The method for calculating the HLB value for $\mathrm{N}$-alkylchitosans and iminochitosans yielded similar values with the exception of films modified with acrolein, which was also confirmed by measuring the lyophilic properties of the reduced Schiff bases presented in Table 2. The decrease in the hydrophobicity of the samples treated with acrolein and borohydride indicated a partial reduction of vinyl groups on the surface.

Table 4 Lyophilic properties of N-alkylchitosans

\begin{tabular}{ccc}
\hline Sample & Contact angle, & Moisture absorption, \\
& deg & $\%$ \\
\hline Chit-NH-CH $2-\mathrm{CH}=\mathrm{CH}_{2}$ or Chit-NH- $\mathrm{CH}_{2}-\mathrm{CH}_{2}-\mathrm{CH}_{3}$ & $95 \pm 3$ & $15 \pm 2$ \\
Chit-NH-CH$-\mathrm{CH}_{2}-\mathrm{CH}\left(\mathrm{CH}_{3}\right)_{2}$ & $92 \pm 2$ & $24 \pm 1$
\end{tabular}




\section{CONCLUSION}

The peculiarities of the surface modification of chitosan films with aldehydes have been studied for the first time, and the dependence of the hydrophilic and hydrophobic properties of the surface of chitosan films on the structure of the hydrocarbon radical of the modifier has been determined. The hydrophobic properties increase upon modification of chitosan films with the corresponding aldehydes with the formation of Schiff bases on their surface in the following order: formic aldehyde < acetaldehyde < propionic aldehyde < salicylic aldehyde < isovaleraldehyde $<$ acrolein.

The potential for use of the surface modification of chitosan-based film materials with low molecular weight aldehydes for the control of wettability, biodegradation time, and physical and mechanical properties has been revealed. Modification of chitosan films with acrolein yielded the largest contact angles up to $110^{\circ}$ and the lowest moisture absorption of approximately $10 \%$, while the initial chitosan was characterized by a contact angle of $65 \pm 5^{\circ}$ and moisture absorption of $40 \%$.

The complete soil destruction of the initial chitosan film materials required 75 to 80 days, while the films modified with aldehydes were destroyed by 60-70\% (wt.) during the same time period, depending on the chemical structure of the modifier.

The cytotoxicity studies of modified chitosan films showed that the resulting materials are non-toxic (cytotoxic index $<50 \%$ ) for human skin cell cultures, which increases their potential use for external wound healing.

\section{References}

1. da Silva D, Kaduri M, Poley M, et al (2018) Biocompatibility, biodegradation and excretion of polylactic acid (PLA) in medical implants 
and theranostic systems. Chem Eng J 340:9-14.

https://doi.org/10.1016/j.cej.2018.01.010

2. Hong Y, Gong Y, Gao C, Shen J (2008) Collagen-coated polylactide microcarriers/chitosan hydrogel composite: Injectable scaffold for cartilage regeneration. J Biomed Mater Res - Part A 85:628-637.

https://doi.org/10.1002/jbm.a.31603

3. Muzzarelli RAA, Biagini G, Bellardini M, et al (1993) Osteoconduction exerted by methylpyrrolidinone chitosan used in dental surgery. Biomaterials 14:39-43. https://doi.org/10.1016/0142-9612(93)90073-B

4. Da Silva CM, Da Silva DL, Modolo L V., et al (2011) Schiff bases: A short review of their antimicrobial activities. J Adv Res 2:1-8. https://doi.org/10.1016/j.jare.2010.05.004

5. Wan Y, Wu H, Yu A, Wen D (2006) Biodegradable polylactide/chitosan blend membranes. Biomacromolecules 7:1362-1372. https://doi.org/10.1021/bm0600825

6. Wang Y, Su Y, Wang W, et al (2019) The advances of polysaccharide-based aerogels: Preparation and potential application. Carbohydr Polym 115242. https://doi.org/10.1016/j.carbpol.2019.115242

7. Wan Y, Fang Y, Wu H, Cao X (2007) Porous polylactide/chitosan scaffolds for tissue engineering. J Biomed Mater Res - Part A 80:776-789. https://doi.org/10.1002/jbm.a.31025

8. Wu T, Zivanovic S, Draughon FA, et al (2005) Physicochemical properties and bioactivity of fungal chitin and chitosan. J Agric Food Chem 53:38883894. https://doi.org/10.1021/jf048202s

9. Wang J, Wang L, Zhou Z, et al (2016) Biodegradable polymer membranes applied in guided bone/tissue regeneration: A review. Polymers (Basel) 8:115-135. https://doi.org/10.3390/polym8040115

10. Singh B, Choi YJ, Park IK, et al (2014) Chemical modification of chitosan with ph-sensitive molecules and specific ligands for efficient DNA transfection and siRNA silencing. J Nanosci Nanotechnol 14:564-576. 
https://doi.org/10.1166/jnn.2014.9079

11. Kean T, Thanou M (2010) Biodegradation, biodistribution and toxicity of chitosan. Adv Drug Deliv Rev 62:3-11.

https://doi.org/10.1016/j.addr.2009.09.004

12. Bakhtiari SSE, Karbasi S, Tabrizi SAH, Ebrahimi-Kahrizsangi R (2019) Chitosan/MWCNTs composite as bone substitute: Physical, mechanical, bioactivity, and biodegradation evaluation. Polym Compos 40:E1622-E1632. https://doi.org/10.1002/pc.25104

13. Babicheva TS, Gegel NO, Shipovskaya AB (2017) Visualization of morphological features of chitosan microtubes during biodegradation. J Phys Conf Ser 917:. https://doi.org/10.1088/1742-6596/917/4/042026

14. Aranaz I, Harris R, Navarro-García F, et al (2016) Chitosan based films as supports for dual antimicrobial release. Carbohydr Polym 146:402-410. https://doi.org/10.1016/j.carbpol.2016.03.064

15. Liu H, Wang C, Li C, et al (2018) A functional chitosan-based hydrogel as a wound dressing and drug delivery system in the treatment of wound healing. RSC Adv 8:7533-7549. https://doi.org/10.1039/c7ra13510f

16. Mohebbi S, Nezhad MN, Zarrintaj P, et al (2018) Chitosan in Biomedical Engineering: A Critical Review. Curr Stem Cell Res Ther 14:93-116. https://doi.org/10.2174/1574888x13666180912142028

17. Intini C, Elviri L, Cabral J, et al (2018) 3D-printed chitosan-based scaffolds: An in vitro study of human skin cell growth and an in-vivo wound healing evaluation in experimental diabetes in rats. Carbohydr Polym 199:593-602. https://doi.org/10.1016/j.carbpol.2018.07.057

18. Morin-Crini N, Lichtfouse E, Torri G, Crini G (2019) Applications of chitosan in food, pharmaceuticals, medicine, cosmetics, agriculture, textiles, pulp and paper, biotechnology, and environmental chemistry. Environ Chem Lett 17:1667-1692. https://doi.org/10.1007/s10311-019-00904-x

19. Ganesan K, Budtova T, Ratke L, et al (2018) Review on the production of polysaccharide aerogel particles. Materials (Basel) 11:2144-2181. 
https://doi.org/10.3390/ma11112144

20. İlk S, Ramanauskaite A, Koç Bilican B, et al (2020) Usage of natural chitosan membrane obtained from insect corneal lenses as a drug carrier and its potential for point of care tests. Mater Sci Eng C Eng C 112:110897. https://doi.org/10.1016/j.msec.2020.110897

21. Takeshita S, Konishi A, Takebayashi Y, et al (2017) Aldehyde Approach to Hydrophobic Modification of Chitosan Aerogels. Biomacromolecules 18:2172-2178. https://doi.org/10.1021/acs.biomac.7b00562

22. Guinesi LS, Cavalheiro ÉTG (2006) Influence of some reactional parameters on the substitution degree of biopolymeric Schiff bases prepared from chitosan and salicylaldehyde. Carbohydr Polym 65:557-561. https://doi.org/10.1016/j.carbpol.2006.01.030

23. Dos Santos JE, Dockal ER, Cavalheiro ÉTG (2005) Synthesis and characterization of Schiff bases from chitosan and salicylaldehyde derivatives. Carbohydr Polym 60:277-282. https://doi.org/10.1016/j.carbpol.2004.12.008

24. Fen (2011) Optical Properties of Crosslinked Chitosan Thin Film with Glutaraldehyde Using Surface Plasmon Resonance Technique. Am J Eng Appl Sci 4:61-65. https://doi.org/10.3844/ajeassp.2011.61.65

25. Argüelles-Monal W, Goycoolea PM, Peniche C, Higuera-Ciapara I (1998) Rheological study of the chitosan/glutaraldehyde chemical gel system. Polym Gels Networks 6:429-440. https://doi.org/10.1016/S0966-7822(98)00032-X

26. Ramachandran S, Nandhakumar S, Dhanaraju MD (2011) Formulation and characterization of glutaraldehyde cross-linked chitosan biodegradable microspheres loaded with famotidine. Trop J Pharm Res 10:309-316. https://doi.org/10.4314/tjpr.v10i3.13

27. Kyzas GZ, Bikiaris DN (2015) Recent modifications of chitosan for adsorption applications: A critical and systematic review. Mar Drugs 13:312337. https://doi.org/10.3390/md13010312

28. Poon L, Wilson LD, Headley J V. (2014) Chitosan-glutaraldehyde 
copolymers and their sorption properties. Carbohydr Polym 109:92-101. https://doi.org/10.1016/j.carbpol.2014.02.086

29. Kimura S, Isobe N, Wada M, et al (2011) Enzymatic hydrolysis of chitosandialdehyde cellulose hydrogels. Carbohydr Polym 83:1850-1853. https://doi.org/10.1016/j.carbpol.2010.10.049

30. Monteiro Jr. OAC, Airoldi C (1999) Some studies of crosslinking chitosanglutaraldehyde interaction in a homogeneous system. Int J Biol Macromol 26:119-128. https://doi.org/10.1016/S0141-8130(99)00068-9

31. Liu Y, Shen X, Zhou H, et al (2016) Chemical modification of chitosan film via surface grafting of citric acid molecular to promote the biomineralization. Appl Surf Sci 370:270-278. https://doi.org/10.1016/j.apsusc.2016.02.124

32. Vallapa N, Wiarachai O, Thongchul N, et al (2011) Enhancing antibacterial activity of chitosan surface by heterogeneous quaternization. Carbohydr Polym 83:868-875. https://doi.org/10.1016/j.carbpol.2010.08.075

33. Marin L, Ailincai D, Mares M, et al (2015) Imino-chitosan biopolymeric films. Obtaining, self-assembling, surface and antimicrobial properties. Carbohydr Polym 117:762-770. https://doi.org/10.1016/j.carbpol.2014.10.050

34. Chernyshova EB, Berezin AS, Tuzhikov OI (2017) Hydrophobization of chitosan-based films with acrolein. Russ J Appl Chem 90:1165-1170. https://doi.org/10.1134/S1070427217070229

35. Yudin VE, Dobrovolskaya IP, Neelov IM, et al (2014) Wet spinning of fibers made of chitosan and chitin nanofibrils. Carbohydr Polym 108:176-182. https://doi.org/10.1016/j.carbpol.2014.02.090

36. Klotzbach T, Watt M, Ansari Y, Minteer SD (2006) Effects of hydrophobic modification of chitosan and Nafion on transport properties, ion-exchange capacities, and enzyme immobilization. J Memb Sci 282:276-283. https://doi.org/10.1016/j.memsci.2006.05.029

37. Bryuzgin E V., Klimov V V., Repin SA, et al (2017) Aluminum surface modification with fluoroalkyl methacrylate-based copolymers to attain 
superhydrophobic properties. Appl Surf Sci 419:454-459.

https://doi.org/10.1016/j.apsusc.2017.04.222

38. Davies JT (1957) A quantitative kinetic theory of emulsion type. I. Physical chemistry of the emulsifying agent. Aquantitive Kinet Theory Emuls Type I Phys Chem Emuls Agent 1:426-438

39. Calmon-Decriaud A, Bellon-Maurel V, Silvestre F (1998) Standard methods for testing the aerobic biodegradation of polymeric materials. Review and perspectives. Blockcopolymers-Polyelectrolytes-Biodegradation 135:207226. https://doi.org/10.1007/3-540-69191-X_3

40. Popryadukhin P V., Dobrovolskaya IP, Yudin VE, et al (2012) Composite materials based on chitosan and montmorillonite: Prospects for use as a matrix for cultivation of stem and regenerative cells. Cell tissue biol 6:82-88. https://doi.org/10.1134/S1990519X12010099

41. El-Hefian EA, Elgannoudi ES, Mainal A, Yahaya AH (2010) Characterization of chitosan in acetic acid: Rheological and thermal studies. Turkish J Chem 34:47-56. https://doi.org/10.3906/kim-0901-38

42. Park SY, Marsh KS, Rhim JW (2002) Characteristics of different molecular weight chitosan films affected by the type of organic solvents. J Food Sci 67:194-197. https://doi.org/10.1111/j.1365-2621.2002.tb11382.x

43. Boinovich LB, Emelyanenko AM (2008) Hydrophobic materials and coatings: principles of design, properties and applications. Russ Chem Rev 77:583-600. https://doi.org/10.1070/rc2008v077n07abeh003775

44. Ma J, Choudhury NA, Sahai Y, Buchheit RG (2011) A high performance direct borohydride fuel cell employing cross-linked chitosan membrane. J Power Sources 196:8257-8264. https://doi.org/10.1016/j.jpowsour.2011.06.009 
Figures
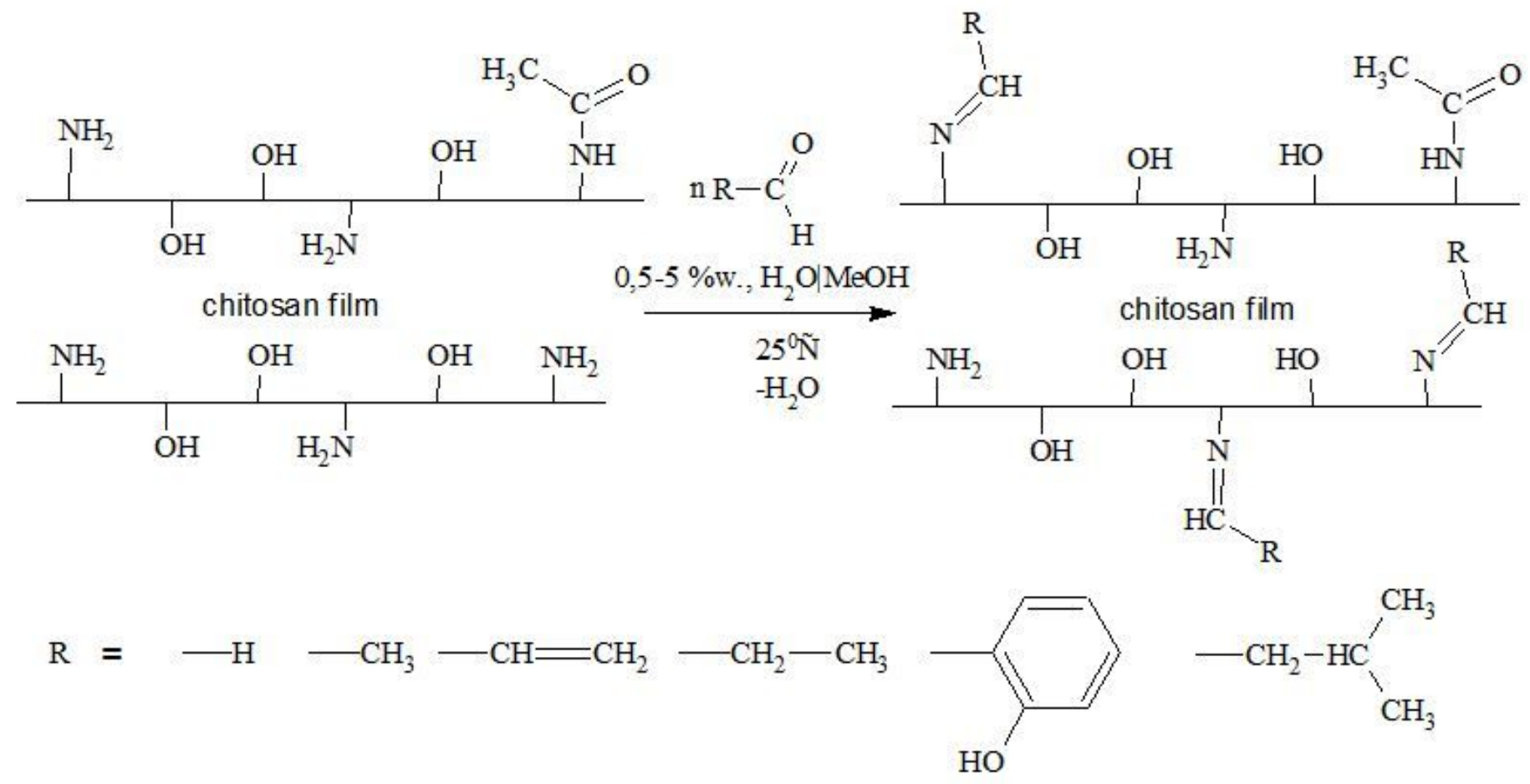

formaldehyde acetaldehyde acrolein propionic aldehyde salicylicaldehyde isovaleric aldehyde

\section{Figure 1}

Interaction of chitosan with aldehydes with the formation of Schiff bases 


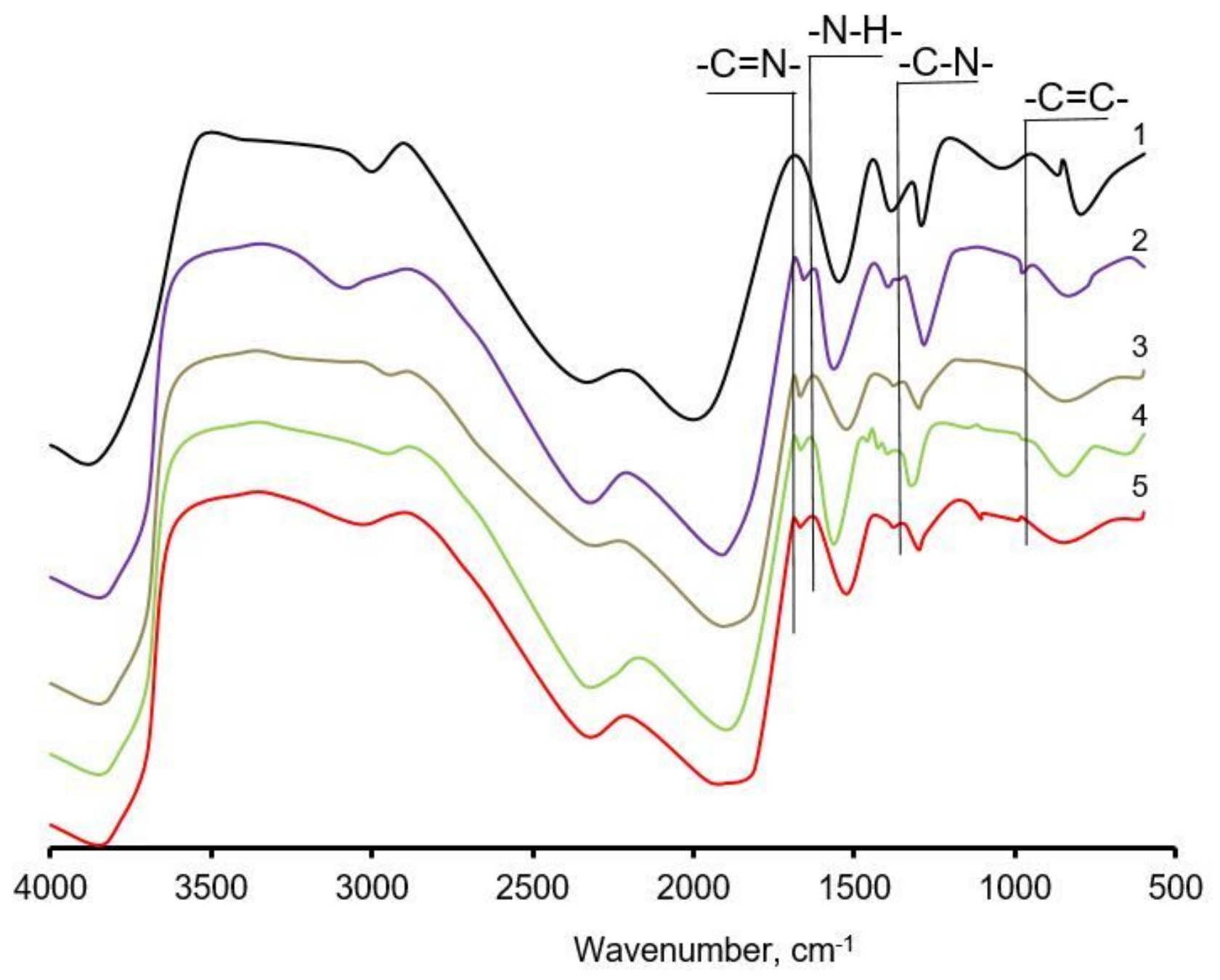

Figure 2

IR spectra of the initial chitosan film (1) and chitosan film treated with $0.0125 \%$ Ac solution (2), $2.5 \%$ PA solution (3), $2.5 \%$ SA solution (4), and $2.5 \%$ IVA solution (5) 


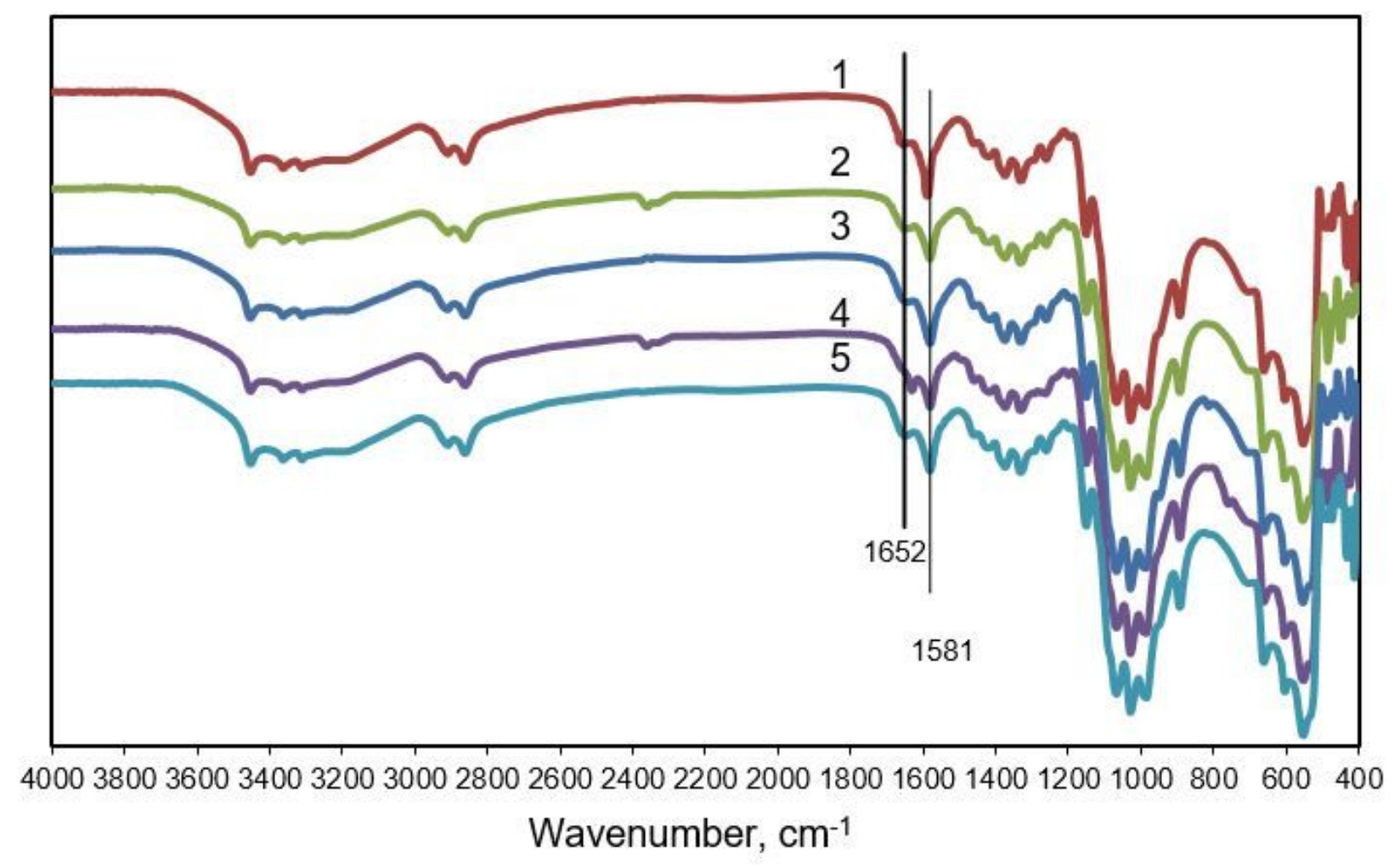

Figure 3

IR spectra (ATR accessory) of the chitosan films (1) treated with $0.0125 \%$ Ac solution (2), 2.5\% PA solution (3), $2.5 \%$ SA solution (4), and $2.5 \%$ IVA solution (5) 

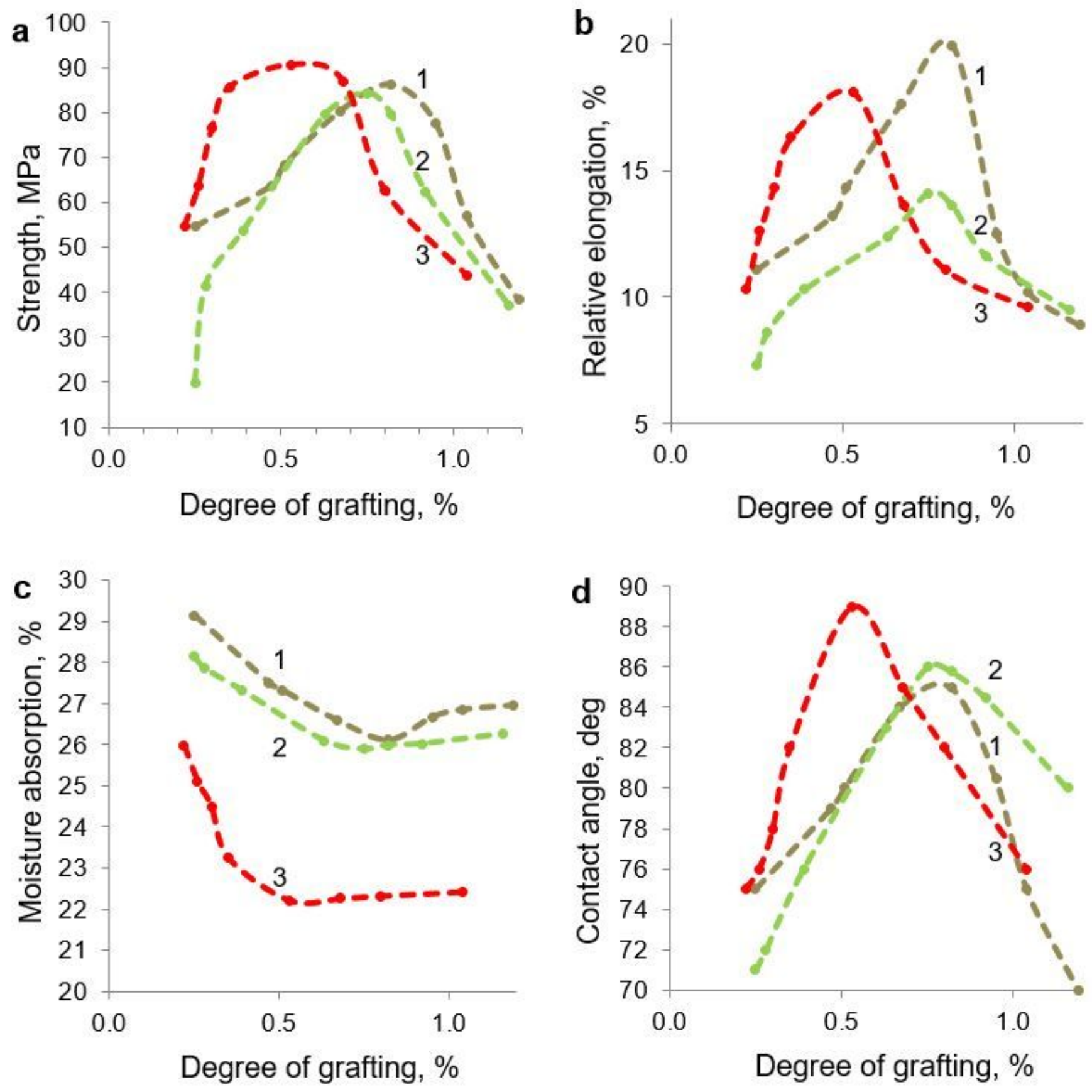

Figure 4

Dependence of the strength characteristics $(a, b)$ and lyophilic characteristics $(c, d)$ of the modified chitosan film on the degree of grafting of modifier: PA (1), SA (2), and IVA (3) 


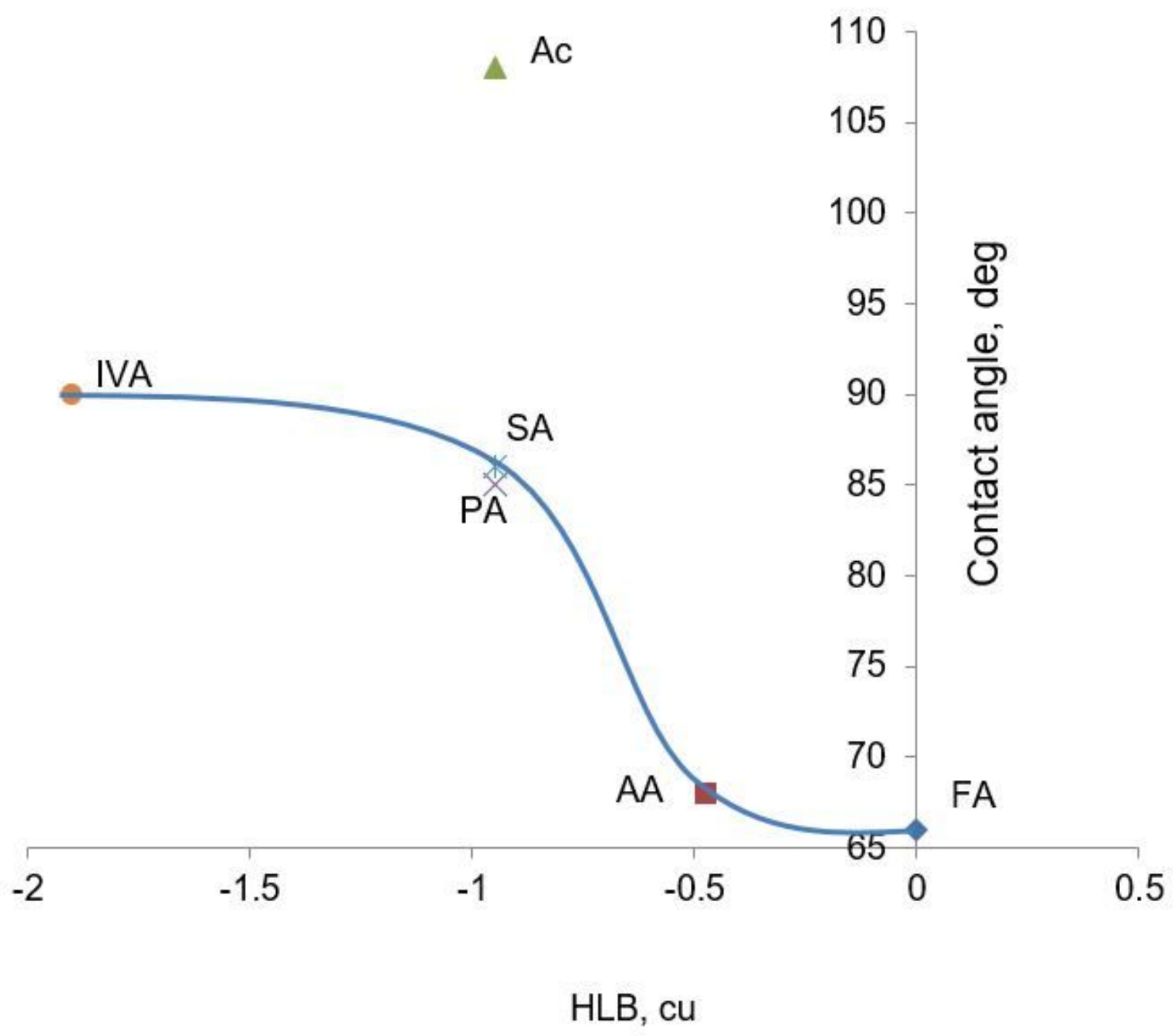

Figure 5

Comparison of the contact angles of modified chitosan films with HLB data of hydrocarbon substituents of aldehydes 


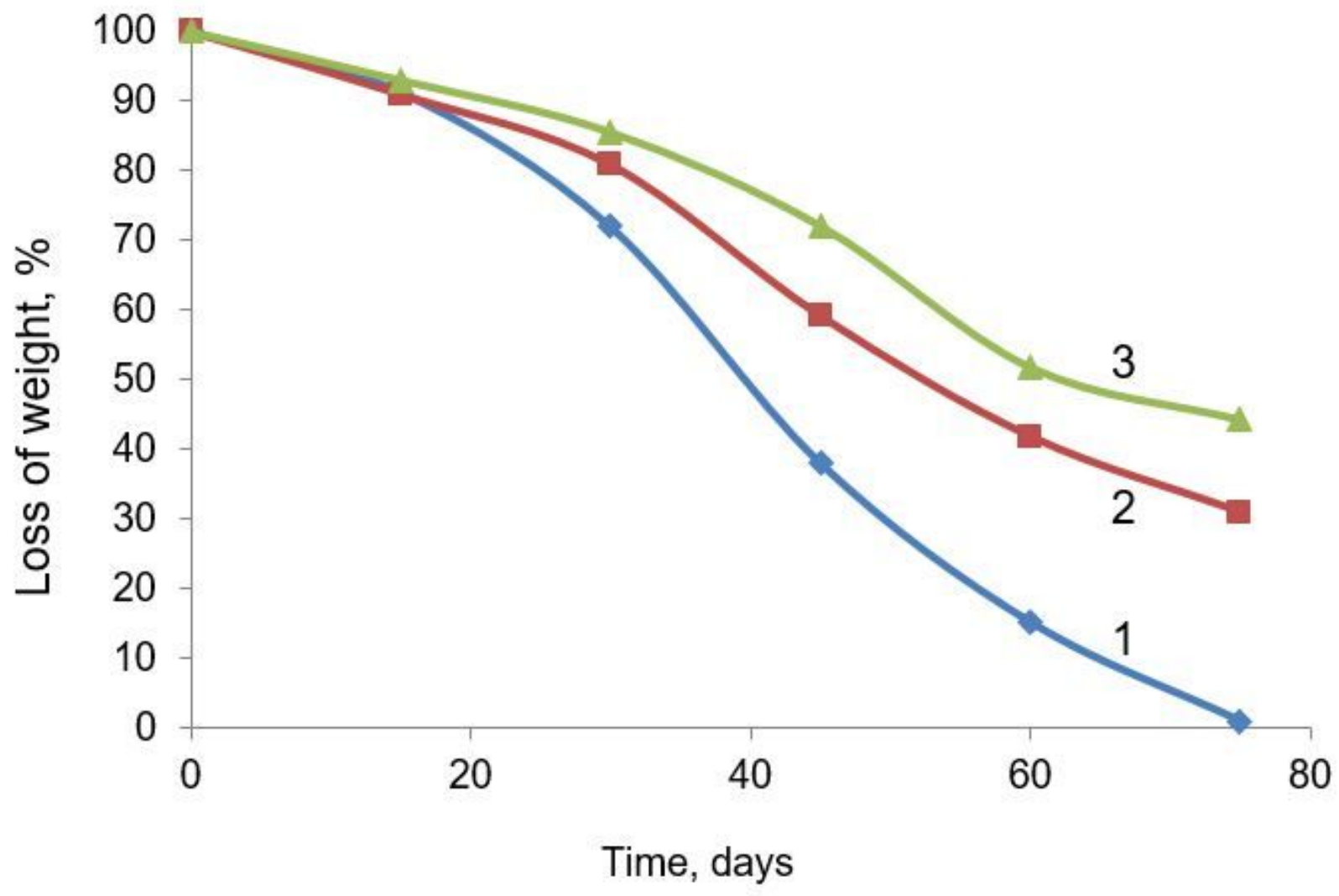

Figure 6

Biodegradability of the initial chitosan films (1) and chitosan films modified with salicylic aldehyde (2) and acrolein (3) 


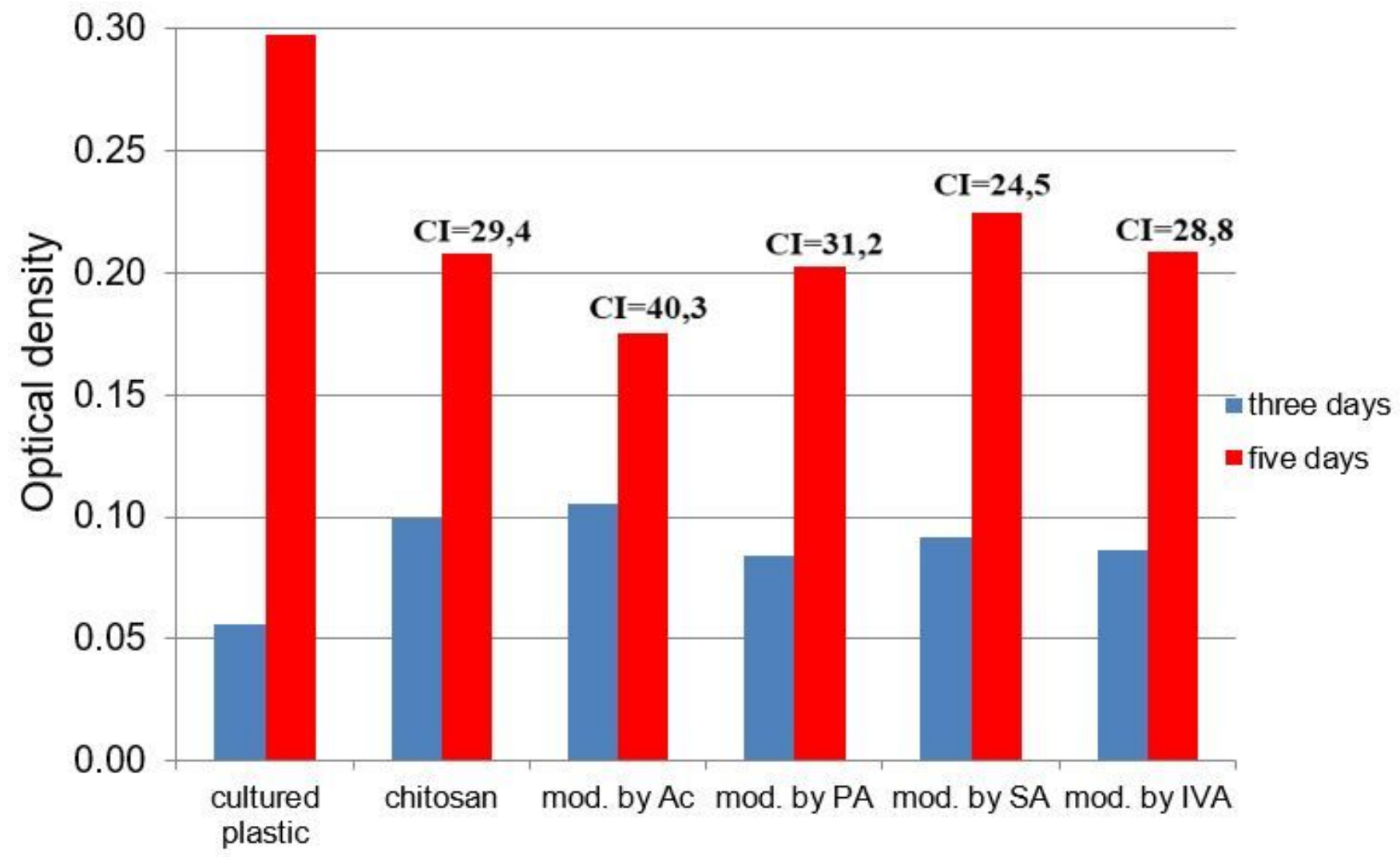

Figure 7

Changes in proliferation of human dermal fibroblasts on unmodified and modified chitosan films

$$
\mathrm{NaBH}_{4}+2 \mathrm{H}_{2} \mathrm{O} \longrightarrow \mathrm{NaBO}_{2}+4 \mathrm{H}_{2}
$$

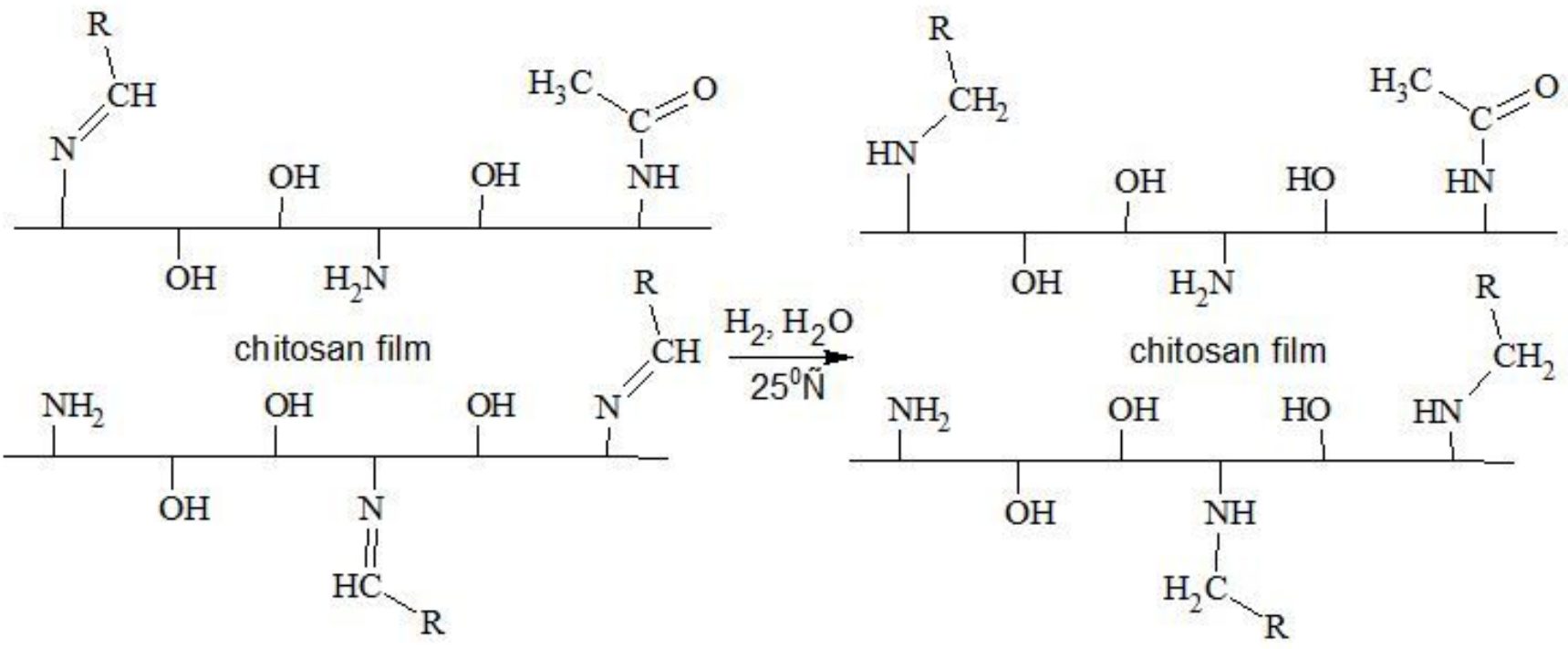

Figure 8 
Reduction of resulting Schiff bases on chitosan films upon modification with aldehydes 